\title{
Aerosol Chemical Characterization and Contribution of Biomass Burning to Particulate Matter at a Residential Site in Islamabad, Pakistan
}

\author{
Imran Shahid ${ }^{1,2^{*}}$, Magdalena Kistler ${ }^{1}$, Muhammad Zeeshaan Shahid ${ }^{3}$, Hans Puxbaum ${ }^{1}$ \\ ${ }^{1}$ Institute of Chemical Technologies and Analytics, Vienna University of Technology, 1060 Vienna, Austria \\ ${ }^{2}$ Department of Space Science, Institute of Space Technology, Islamabad 44000, Pakistan \\ ${ }^{3}$ Theoretical Research Institute of Pakistan Academy of Science (TRIPAS), Islamabad 44000, Pakistan
}

\begin{abstract}
Air pollution creates a very serious problem in developing countries, and scarce information is available about the nature of pollutants. This study describes the chemical composition of particulate matter (TSP and PM 10 ), including marker compounds pointing to pollution sources, and estimates the contribution of biomass smoke to organic carbon (OC) and particulate matter (PM) at a residential site in Islamabad during the winter period in December 2007. Levoglucosan and its relationship with other anhydrosaccharides were used to estimate the biomass burning contribution, and polyols and primary and secondary saccharides were investigated regarding biological aerosol. Polyols and primary saccharides contribute a small fraction of the total $\mathrm{PM}_{10}$ and TSP mass, whereas anhydrosaccharides contribute more than $90 \%$ in both the $\mathrm{PM}_{10}$ and TSP. A significant contribution from biomass smoke has also been found in Islamabad, forming $10 \%$ of the TSP and $18 \%$ of the $\mathrm{PM}_{10}$ mass. The analysis of the distributions of saccharide concentrations between the TSP and PM 10 fractions shows that anhydrosaccharides, viz., levoglucosan, mannosan and galactosan, all of which are directly related to the combustion of biomass, are mainly present in the $\mathrm{PM}_{10}$. The concentration of TSP varied from $218 \mu \mathrm{g} \mathrm{m}^{-3}$ to $468 \mu \mathrm{g} \mathrm{m}{ }^{-3}$ (mean: $343 \mu \mathrm{g} \mathrm{m}^{-3}$ ), and $\mathrm{PM}_{10}$ concentrations were in the range of 89-304 $\mu \mathrm{g} \mathrm{m}^{-3}$ (mean: $194 \mu \mathrm{g} \mathrm{m}^{-3}$ ). A good correlation was observed between $\mathrm{PM}_{10}$, TSP and $\mathrm{Ca}^{2+}$, which implies that mineral/road dust may be a major contributor to the PM in Islamabad.
\end{abstract}

Keywords: Particulate matter; Urban air pollution; Biomass burning aerosol; Saccharides.

\section{INTRODUCTION}

Atmospheric pollution is increasing day by day all over world due to rapid urbanization, industrialization and environmental degradation especially in developing countries like Pakistan, India and China. High levels of pollutants which are not only damaging the cultural heritage but also very harmful to human health especially in urban areas, where these concentrations are so high that it's very difficult to breathe. Ghude et al. (2016) established association of premature mortality in India due to $\mathrm{PM}_{2.5}$ and ozone exposure while Chate et al. (2010) and Kaushar et al. (2013) assessed the population exposure to environmental pollutants during Commonwealth Games in India while Beig et al. (2013) examined the population exposure during Deepavali Festival in India. All these studies reported higher risk of human health due to air pollution. Atmospheric aerosol or particulate matter $(\mathrm{PM})$ is chemically complex and a dynamic mixture

\footnotetext{
${ }^{*}$ Corresponding author.

E-mail address: imran.shahid@grel.ist.edu.pk
}

of solid and liquid particles. The major sources of these particles are combustion generated particles, sea salt spray, dust, vehicles exhaust, industrial stacks, construction activities, fossil fuel combustion and biomass burning (Dutkiewicz et al., 2009). There are limited studies available regarding chemical nature of atmospheric aerosol in Pakistan region (Alam et al., 2014; Bibi et al., 2015; Shahid et al., 2015a, b, 2016; Alvi et al., 2018; Shahid et al., 2018). There are limited data available like Stone et al. (2010) on chemical characterization and source apportionment of coarse particulate matter in Lahore; Kamal et al. (2015) has reported risk related to $\mathrm{PAH}$ during traditional cooking in Pakistan and Singh et al. (2017) has reported organic aerosol over Indo-Gangetic Plain and sources and climate implications. Ghauri et al. (2007) reported TSP and $\mathrm{PM}_{10}$ level in different cities of Pakistan, the maximum particulate matter (TSP and $\left.\mathrm{PM}_{10}\right)$ concentrations were observed at Lahore $\left(996 \mu \mathrm{g} \mathrm{m}^{-3}\right.$ and $368 \mu \mathrm{g} \mathrm{m}^{-3}$ respectively) followed by Quetta $\left(778 \mu \mathrm{g} \mathrm{m}^{-3}\right.$, $\left.298 \mu \mathrm{g} \mathrm{m}^{-3}\right)$ and in Karachi $\left(410 \mu \mathrm{g} \mathrm{m}^{-3}, 302 \mu \mathrm{g} \mathrm{m}^{-3}\right)$.

There is limited information available on the comprehensive characterization of particulate matter in Islamabad. The heavy metals concentration and their sources in Islamabad atmosphere have been reported many 
times in previous studies (Parekh et al., 2000; Shah et al., 2004; Rajput et al., 2005; Shah et al., 2006, 2007, 2010). Parekh et al. (2001) reported TSP concentration at Islamabad and Karachi, at Islamabad daily TSP concentrations varied in the range of 428-998 $\mu \mathrm{g} \mathrm{m}^{-3}$ (mean: $691 \mu \mathrm{g} \mathrm{m}^{-3}$ ); even at a relatively remote site of the city Saidpur TSP loading was high as $145-448 \mu \mathrm{g} \mathrm{m}^{-3}$. Rajput et al. (2005) reported the TSP and elemental concentrations in the area around the industrial sector (I-9), TSP concentration was found to be double $\left(279 \mu \mathrm{g} \mathrm{m}^{-3}\right)$ than in the sector F-7 $\left(133 \mu \mathrm{g} \mathrm{m}^{-3}\right)$. Shah and Shaheen (2010) has reported seasonal behaviors in elemental composition of atmospheric aerosols collected in Islamabad, and found good correlation between TSP and metal in Islamabad atmosphere. Saddique et al. (2012) discussed the air quality in Islamabad using metal concentration by X-ray fluorescence spectrometry. The metal concentration was found less than from megacities of Pakistan, i.e., Karachi, Lahore, and Faisalabad. Qadir et al. (2012) reported evaluation of trace elemental composition of aerosols in the atmosphere of Rawalpindi and Islamabad using radio analytical methods. While A. Rasheed discussed the air quality of Islamabad by reporting concentrations of $\mathrm{PM}_{2.5}$ and gaseous species and found that $\mathrm{PM}_{2.5}$ and $\mathrm{NO}$ concentrations exceeded WHO limits. Bulbul et al. (2018) reported the $\mathrm{PM}_{10}$ concentrations and their structure morphology in Islamabad during winter fog period (December-March). Awais et al. (2018) assessed the aerosol optical properties using remote sensing over twin cities of Pakistan, i.e., Islamabad and Rawalpindi. There is exponential growth in vehicle population in city since 2007. However, introduction of new technologies and emission standard has reduced emission but their volume is still huge. Shah and Zeeshan (2016) reported estimation of light-duty vehicle emissions in Islamabad and climate co-benefits of improved emission standards implementation and observed that highest overall emissions (59\%) were on arterials, followed by residential roads (24\%) and highways (17\%) with higher emissions during morning (8-10 a.m.) and evening (4-6 p.m.) rush hours.

All these studies over Islamabad has reported continuous degradation of air quality in the city, no study has given the comprehensive characterization of atmospheric aerosol and most of these studies are short-term. Unfortunately, no continuous air quality data is available for Pakistan cities and scientific studies are also short-term due to lack of facilities. This study is an attempt to characterize particulate matter, i.e., carbonaceous species, soluble ions, anhydrosugars and sugar alcohols in both TSP and $\mathrm{PM}_{10}$ size fraction at a residential site in Islamabad, Pakistan.

\section{EXPERIMENTAL}

\section{Site Description}

Islamabad is the capital of Pakistan and is situated at an elevation about $500 \mathrm{~m}$ above sea level (latitude: $33.7294^{\circ} \mathrm{N}$ and longitude: $73.0931^{\circ} \mathrm{E}$ ) with a population of about two million and an area about $906 \mathrm{~km} 2$. The climate is subtropical with four distinct seasons, summer (June-August), autumn (September-November), winter (December-February) and spring (March-May). The average wind magnitude and wind vectors at 2 meter height, average over 2007 to 2017 has been shown in Fig. 1. The average annual rainfall is $1143 \mathrm{~mm}$. The city is divided into residential, commercial, industrial and diplomatic zones; some of them are shown in the map of Islamabad (Fig. 2). The sampling was done in F-11 Sector Islamabad. This site is a residential area and away from commercial and traffic zone of the city. There are small villages close to sampling sites that mostly burn biomass for cooking and heating purposes. There is no industry and heavy traffic zone in proximity of the sampling site. The site location represented here in Fig. 2 is recent of 2018. In 2007 when the sampling was done the Sector E-11 (the upper left side in Figure) was not developed. In last 10 years there is increase in city population and lot of deforestation in lieu of housing societies and urbanization. The city is expanding in all directions and suburbs are now part of the city.

\section{Sampling}

Daily 24 hours' samples of TSP and $\mathrm{PM}_{10}$ were collected on Whatman filters using Thermo-Electron Cooperation highvolume sampler at flow rate of $1.018 \mathrm{~m}^{3} \mathrm{~min}^{-1}$ for TSP and $0.962 \mathrm{~m}^{3} \mathrm{~min}^{-1}$ for $\mathrm{PM}_{10}$. Filters was pre-conditioned at $550^{\circ} \mathrm{C}$ and humidity room for 24 hours before and after sampling in order to avoid artefacts. Filters were weighed on site and store at $4^{\circ} \mathrm{C}$. Twelve samples for TSP and $\mathrm{PM}_{10}$, starting from 3 December 2007 to 16 December 2007 (no sampling on 8 and 15 December), were collected. After collection, these samples were stored in a freezer and transported to Vienna, Austria, by air luggage for analysis.

\section{Experimental Methods \\ Carbonaceous Species}

TC (total carbon) was determined by a combustion method, where all material on the filter is combusted in pure oxygen at $1000^{\circ} \mathrm{C}$ and the resulting $\mathrm{CO}_{2}$ is measured by non-dispersive IR photometry (NDIR, Maihak). The calibration procedure was done using tartaric acid dyed in aluminum foil. The elemental carbon (EC) was determined by a two-step combustion method described by Cachier et al. (1989). In the first step filters were heated for 2 hours at $340^{\circ} \mathrm{C}$ in an oxygen atmosphere to remove organic carbon (OC). In a subsequent second step (high-temperature step) filters was heated at $1000^{\circ} \mathrm{C}$, in $\mathrm{O}_{2}$ atmosphere, $\mathrm{EC}$ (and carbonate carbon, IC) is oxidized. $\mathrm{CO}_{2}$ originating in this step is detected by an NDIR analyzer. The two major factors affecting the uncertainty of EC and OC measurements are the sampling artefacts related to $\mathrm{OC}$, and the analytical challenge of separating EC from OC. Due to glass fiber filter samples thermal-optical methods were not used for EC measurement. Carbonate carbon (CC) was determined by two-step combustion method described by Jankowski et al. (2008). In first step filter samples was kept in an oven at $480^{\circ} \mathrm{C}$ in oxygen atmosphere and in second step filters are combusted at $1000^{\circ} \mathrm{C}$ and emitted $\mathrm{CO}_{2}$ was determined by non-dispersive NDIR, resulting values are reported as CC. While the organic carbon was calculated using following relationship $\mathrm{OC}=\mathrm{TC}-\mathrm{EC}-\mathrm{CC}$. 


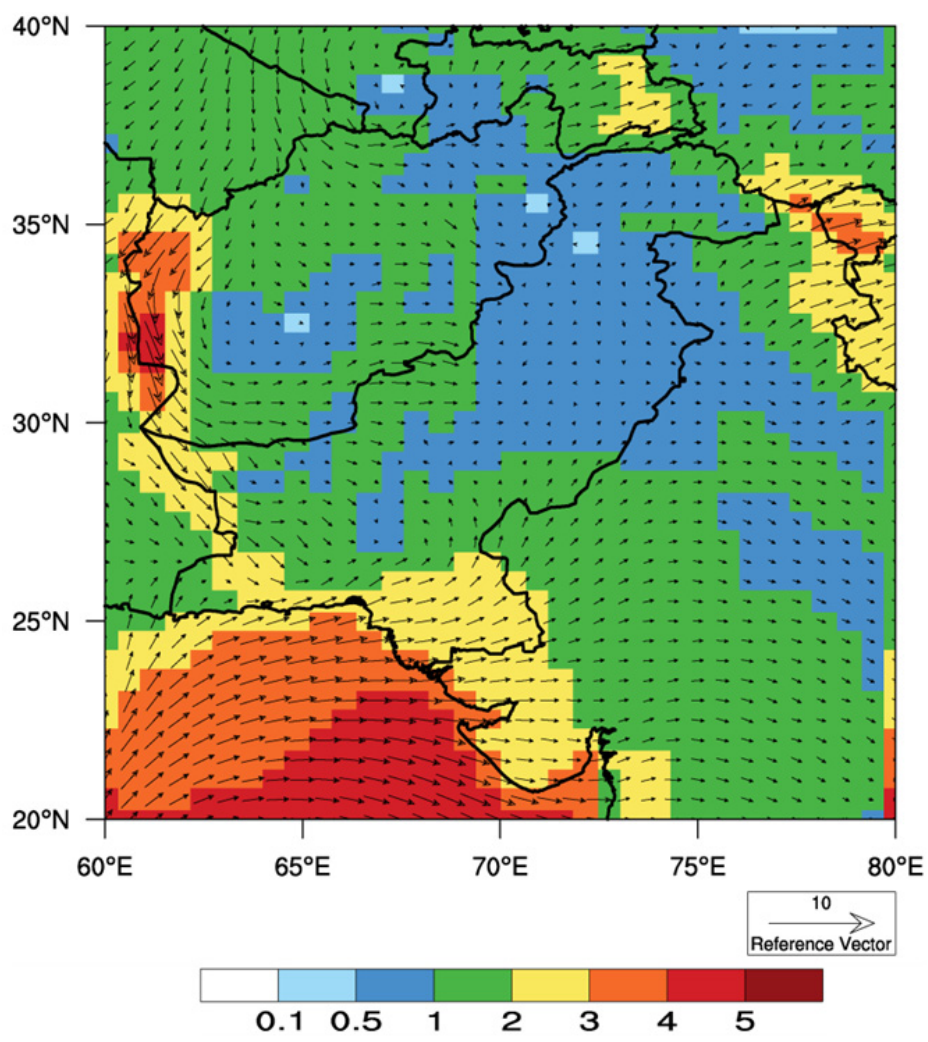

Fig. 1. Wind Magnitude and Wind vectors at 2 meter height, average over 2007 to 2017 (Merra 2 satellite data).

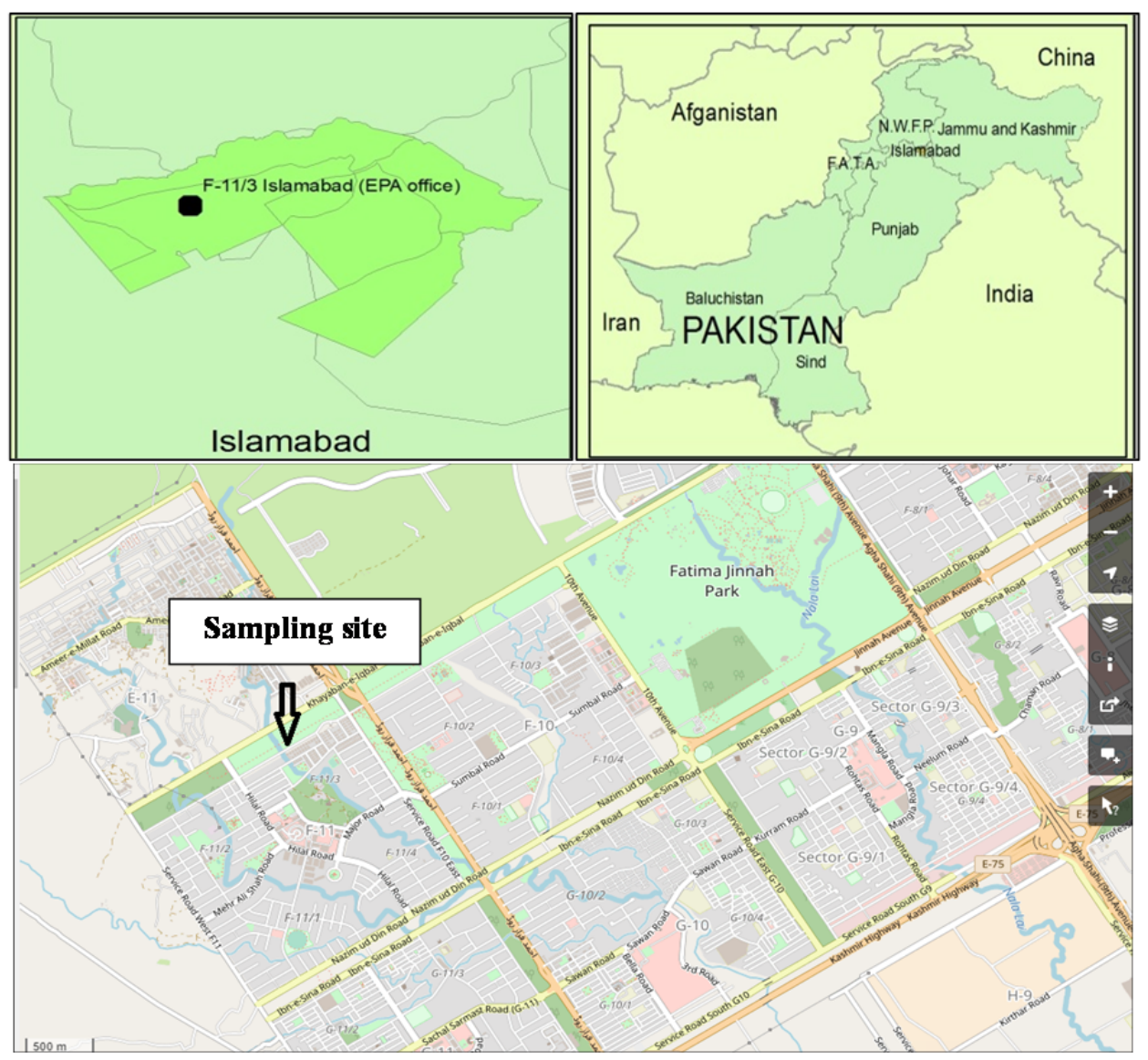

Fig. 2. Sampling site in Islamabad (This figure is taken from openstreetmap.org). 


\section{Saccharides}

The determination of saccharides was performed with an improved high-performance anion-exchange chromatography with pulsed amperometric detection (HP AEC-PAD) according to method described by Iinuma et al. (2009). The method uses $\mathrm{NaOH}$ gradient $(480-650 \mathrm{mM})$ which allows a good separation of levoglucosan and arabitol, both relevant constituents of atmospheric aerosols in Pakistan (Shahid et al., 2016). Circular filter aliquots $\left(1.6 \mathrm{~cm}^{2}\right)$ were extracted with $3 \mathrm{~mL}$ of ultra-pure water (Milli-Q, Milipore, 18.2 M $\Omega$ ) under ultrasonic agitation for $30 \mathrm{~min}$. The extracts were centrifuged and filtered through PET syringe filters $(0.45 \mu \mathrm{m}$, Chromafil, Macherey-Nagel) to remove insoluble material. Analytical procedure was carried out using Dionex ICS-3000 system consisting of a gradient pump, Carbopac MA1 column and electrochemical detector with working gold electrode. For quantification, an external calibration based upon mixed standards prepared from frozen 1000 ppm stock solutions (self-prepared once a year by weighing of pure solids supplied by Fluka or SigmaAldrich) was used. Five mixed standard solutions containing xylitol, levoglucosan, arabitol, mannosan, trehalose (mycose), mannitol, galactosan, glucose, galactose, fructose and sucrose in the concentration range of $0.05-10 \mathrm{ppm}$ were prepared each week and were stored aliquoted in a freezer. A fivepoint calibration curve was run at the beginning and end of each measurement sequence to assure the accuracy of calibration with relation to measurement conditions. Blank filters were prepared in the same way as samples and measured to correct the possible contaminations related to extraction or to filter material itself, as glass fibers are known to contain relatively high amount of adsorbed organic carbon.

The detection limits (calculated as threefold standard deviation of multiple analysis of the lowest standard) were at $0.008 \mu \mathrm{g} \mathrm{m}^{-3}$ for arabitol and levoglucosan and $0.003 \mu \mathrm{g} \mathrm{m}^{-3}$ for the other determined saccharides. The method uncertainty based upon multiple analyses of distinctly extracted samples is $9 \%$. All measured blanks were free of saccharides chosen for determination (mostly no visible peaks at all or if observed then under the detection limit).

\section{Inorganic Ions}

Anions $\left(\mathrm{Cl}^{-}, \mathrm{NO}_{3}{ }^{-}, \mathrm{SO}_{4}{ }^{2-}\right)$ were eluted from glass fiber filter aliquots by washing with high-purity water (Millipore Milli-Q plus 185). After sonicating and centrifuging, the extract was analyzed on an AS12A anion-exchange column, with an ASRS Ultra II auto-regenerating suppressor, and a model CD20 conductivity cell detector (the whole system from Dionex). Cations $\left(\mathrm{Na}^{+}, \mathrm{K}^{+}, \mathrm{NH}_{4}^{+}, \mathrm{Mg}^{2+}\right.$ and $\left.\mathrm{Ca}^{2+}\right)$ were eluted with $0.1 \% \mathrm{v} \mathrm{v}^{-1}$ methane sulphonic acid, which is the chromatography eluent. After sonication and centrifugation, the extract was analyzed by isocratic ion chromatography: a system consisting of CS12A cation-exchange column, self-regenerating CSRS suppressor and a conductivity detector (Dionex, ICS3000). Blanks prepared in the same method as samples were measured and all results were corrected by blank values. Quantification was done based upon external standards measured along with the samples. For ions, all blanks were either in the same order of magnitude as the detection limit only $\mathrm{Cl}^{-}$was a bit higher (5 times) and $\mathrm{Na}^{+}$was 10 times higher, which is a typical observation for this kind of filter material. The detection limits were $0.03 \mu \mathrm{g} \mathrm{m}^{-3}$ for chloride and sodium and $0.007 \mu \mathrm{g} \mathrm{m}^{-3}$ for other ions. The method uncertainty based upon multiple analyses of distinctly extracted samples is $12 \%$. Quality assurance comprised reference solution measurements (Thermo Scientific) and regular ring measurements (World Meteorological Organization).

\section{RESULT AND DISCUSSION}

\section{PM $_{10}$ and TSP Concentrations and Main Aerosol Components}

The average concentration of $\mathrm{PM}_{10}$ and TSP for measured within the study period was $194 \pm 60 \mu \mathrm{g} \mathrm{m}^{-3}$ and $343 \pm$ $87.8 \mu \mathrm{g} \mathrm{m}^{-3}$ which are comparable with other cities of the region like TSP in Delhi is $416.34 \pm 223 \mu \mathrm{g} \mathrm{m}^{-3}$ (Khillare et al., 2004). Sandilya et al. (2007) have reported higher TSP for Delhi, i.e., $687 \pm 117.4 \mu \mathrm{g} \mathrm{m}^{-3}$ and $\mathrm{PM}_{10}$ in Delhi $268 \pm 39 \mu \mathrm{g} \mathrm{m}^{-3}$. Bhaskar and Mehta have reported $\mathrm{PM}_{10}$ concentrations in Ahmadabad, India, ranging from 17$327 \mu \mathrm{g} \mathrm{m}^{-3}$ respectively. The $\mathrm{PM}_{10}$ makes about $50-60 \%$ of the TSP. The difference between TSP and $\mathrm{PM}_{10}$ varies from $78 \mu \mathrm{g} \mathrm{m}^{-3}$ to $196 \mu \mathrm{g} \mathrm{m}^{-3}$ with an average of $148 \mu \mathrm{g} \mathrm{m}^{-3}$. The main constituent of the coarse $\left(\right.$ TSP-PM $\left.\mathrm{PM}_{10}\right)$ fraction is water-soluble calcium. $\mathrm{Ca}^{2+}$ concentrations in TSP is $42.6 \mu \mathrm{g} \mathrm{m}^{-3}$ of which $50 \%$ contributes to the coarse fraction. A good correlation between water-soluble calcium in TSP and $\mathrm{PM}_{10}$ with $\mathrm{r}^{2}=0.94$ and $\mathrm{r}^{2}=0.83$ respectively as shown in Fig. 3 indicates the mineral dust is major contributor to both $\mathrm{PM}_{10}$ and TSP fractions in Islamabad.

Total carbonaceous fraction (EC, OC and CC) was the main contributor to $\mathrm{PM}_{10}$ mass and no significant difference was found between total carbon concentration in TSP and $\mathrm{PM}_{10}\left(63.2 \mu \mathrm{g} \mathrm{m}^{-3}\right.$ and $\left.60.2 \mu \mathrm{g} \mathrm{m}^{-3}\right)$. The average EC concentrations were $17.8 \mu \mathrm{g} \mathrm{m}^{-3}$ for TSP and $16.5 \mu \mathrm{g} \mathrm{m}^{-3}$ for $\mathrm{PM}_{10}$ which is given in Table 1. EC concentration were not reported for Islamabad before, however, compared to other cities, e.g., Karachi, Lahore, Mumbai, Allahabad, Ahmedabad, Dhaka, Hangzhou and Beijing. The concentrations are comparable even if artefacts in the range of $10 \%$ resulting from the thermal EC determination method are considered. EC was used as tracer for traffic emissions (Turpin and Huntzicker, 1995; Salma et al., 2004). Some studies have reported higher EC and BC concentrations in South Asian cities, e.g., for Dhaka $\mathrm{OC}$ and $\mathrm{BC}$ varied from 5-96 $\mu \mathrm{g} \mathrm{m}^{-3}$ and 4-48 $\mu \mathrm{g} \mathrm{m}^{-3}$ respectively (Begum et al., 2012) while average $\mathrm{OC}$ and $\mathrm{BC}$ concentration reported by Salam et al. (2003) was $45.9 \mu \mathrm{g} \mathrm{m}^{-3}$ and $22.0 \mu \mathrm{g} \mathrm{m}^{-3}$ respectively. High EC shares in Islamabad in this study (30\% of the total carbon fraction) can be related to the significant influence of traffic, including two-stroke vehicles and diesel engines. Such situation was also shown previously for another Pakistani city, Lahore (Zhang et al., 2008b). The correlation between EC and nitrate ions (Table S1) underlines that a large part of EC may be related to the regional traffic and fossil fuel combustion and biomass 


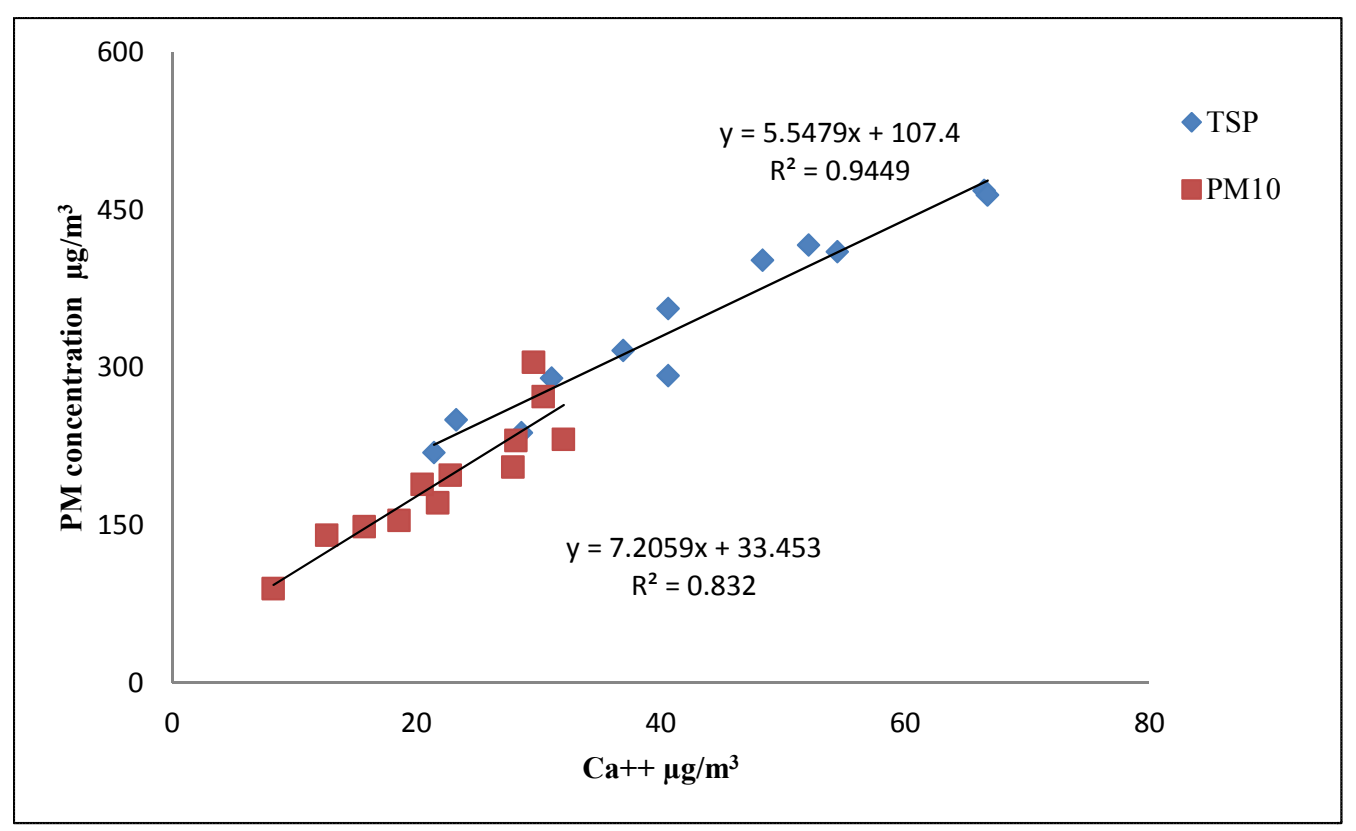

Fig. 3. Linear regression plot between $\mathrm{PM}_{10}$ and TSP with water soluble $\mathrm{Ca}^{++}$.

burning are significant sources of EC, which is alike given by the correlation with suitable tracers: $\mathrm{K}^{+}$, levoglucosan and $\mathrm{Cl}^{-}$. The $\mathrm{OC}$ concentration at Islamabad was $38 \mu \mathrm{g} \mathrm{m}^{-3}$ and $40 \mu \mathrm{g} \mathrm{m}^{-3}$ for TSP and $\mathrm{PM}_{10}$ respectively.

Also, the ratio OC/EC can also be used as an indicator for sources of carbonaceous species (Schauer et al., 1999; Andreae et al., 2001; Schauer et al., 2001; Sudheer et al., 2008; Sandradewi et al., 2008; Rastogi et al., 2009; Ram et al., 2010). Low OC/EC ratio (1-4.2) indicates fresh aerosols, like the diesel and gasoline exhaust influences (Schauer et al., 1999, 2001) while for biomass burning a OC/EC $=7.7$ has been reported by Zhang et al. (2007) and very high $\mathrm{OC} / \mathrm{EC}$ ratio greater than 14 have been reported for forest fire, where also a large impact of secondary organic aerosol formation is expected (Gray et al., 1986; Turpin et al., 1990; Hidemann et al., 1991; Chow et al., 1996).

In the present study, OC/EC ratio varies from 2.2 to 3.3 with an average of 2.5 for $\mathrm{PM}_{10}$ and 2.1 for TSP. This implies that fresh combustion aerosol, e.g., diesel and gasoline exhaust, as indicated by high EC concentrations itself is an important source of PM at Islamabad. A strong correlation between EC and OC in both fractions with $\mathrm{r}^{2}=$ 0.94 for $\mathrm{PM}_{10}$ and $\mathrm{r}^{2}=0.84$ for TSP has been observed which indicates that they have common sources. The OC/EC ratio in Islamabad is comparable with other cities of region like Mumbai (India) and Dhaka, Bangladesh (Salam et al., 2003), while it lower than in Ahmedabad, India (Rastogi et al., 2009), where biomass combustion is found to be major source of carbonaceous species.

\section{Water Soluble Ions}

Water soluble inorganic ions: calcium $\left(\mathrm{Ca}^{2+}\right)$, magnesium $\left(\mathrm{Mg}^{2+}\right)$, sodium $\left(\mathrm{Na}^{+}\right)$, ammonium $\left(\mathrm{NH}_{4}^{+}\right)$, potassium $\left(\mathrm{K}^{+}\right)$, sulphate $\left(\mathrm{SO}_{4}{ }^{2-}\right)$, nitrate $\left(\mathrm{NO}_{3}{ }^{-}\right)$, and chloride $\left(\mathrm{Cl}^{-}\right)$were found in atmospheric aerosol samples collected in Islamabad during winter period. The average concentrations of soluble ions are given in Table 1. The $\mathrm{Ca}^{2+}, \mathrm{SO}_{4}{ }^{2-}$ and $\mathrm{NO}_{3}{ }^{-}$ concentrations were found major quantity in Islamabad. The $\mathrm{Ca}^{2+}$ concentration in Islamabad varied from 8-32 $\mu \mathrm{g} \mathrm{m}^{-3}$ with an average of $22 \mu \mathrm{g} \mathrm{m}^{-3}$ for $\mathrm{PM}_{10}$ and for TSP it varied from $21-66 \mu \mathrm{g} \mathrm{m}^{-3}$ with an average of $42 \mu \mathrm{g} \mathrm{m}^{-3}$. The high $\mathrm{Ca}^{2+}$ concentration has also been reported by Shahid et al. (2016) in Karachi and Ghude et al. (2017) in Delhi. The contribution of $\mathrm{Ca}^{2+}$ to total PM mass was $12.5 \%$ in Islamabad while Ghude et al. (2017) reported $\mathrm{Ca}^{2+}$ contribution to PM was $14 \%$. Thus, high $\mathrm{Ca}^{2+}$ concentration in Islamabad is not an anomaly. Khawaja et al. (2009) also reported a strong correlation between TSP, $\mathrm{PM}_{10}$ and $\mathrm{Ca}^{2+}$ indicated mineral dust contributions. The average concentration of the secondary inorganic constituents $\mathrm{NH}_{4}^{+}, \mathrm{NO}_{3}^{-}$and $\mathrm{SO}_{4}{ }^{2-}$ were $1.3 \mu \mathrm{g} \mathrm{m}^{-3}, 12 \mu \mathrm{g} \mathrm{m}^{-3}$ and $7.8 \mu \mathrm{g} \mathrm{m}^{-3}$ respectively for TSP and $1.3 \mu \mathrm{g} \mathrm{m}^{-3}, 11 \mu \mathrm{g} \mathrm{m}^{-3}$ and $6.7 \mu \mathrm{g} \mathrm{m}^{-3}$ for $\mathrm{PM}_{10}$. $\mathrm{NO}_{3}^{-}$was correlating with ammonium, as well with elemental carbon and the concentrations of nitrate are comparable with Hangzhou (China) and Beijing (China) but higher, if compared to Mumbai (India), Ahmedabad (India), Allahabad (India) and Dhaka (Bangladesh). The $\mathrm{SO}_{4}{ }^{2-}$ concentrations in Islamabad were found to be comparable with concentration in Mumbai but less than other Asian cities like Dhaka, Beijing, Hangzhou and Karachi. The $\mathrm{SO}_{4}{ }^{2-}$ has only correlation with $\mathrm{NH}_{4}{ }^{+}$indicating that it can be present as ammonium sulphate and thus should be rather seen as component of trans-regional pollution transport, formed with ammonia resulting from agricultural activities outside the city (Rastogi et al., 2009). $\mathrm{Cl}^{-} / \mathrm{Na}^{+}$ratio of 1.8 has been reported for sea water, while at Islamabad $\mathrm{Cl}^{-} / \mathrm{Na}^{+}$was 0.6-0.73 in TSP and $\mathrm{PM}_{10}$ indicating the $\mathrm{Cl}^{-}$depletion during long-range transport. The comparison between the sum of cations and anions in equivalent values have been shown in Fig. 4, a linear relationship is present if carbonates, calculated out of CC are added to anions. 


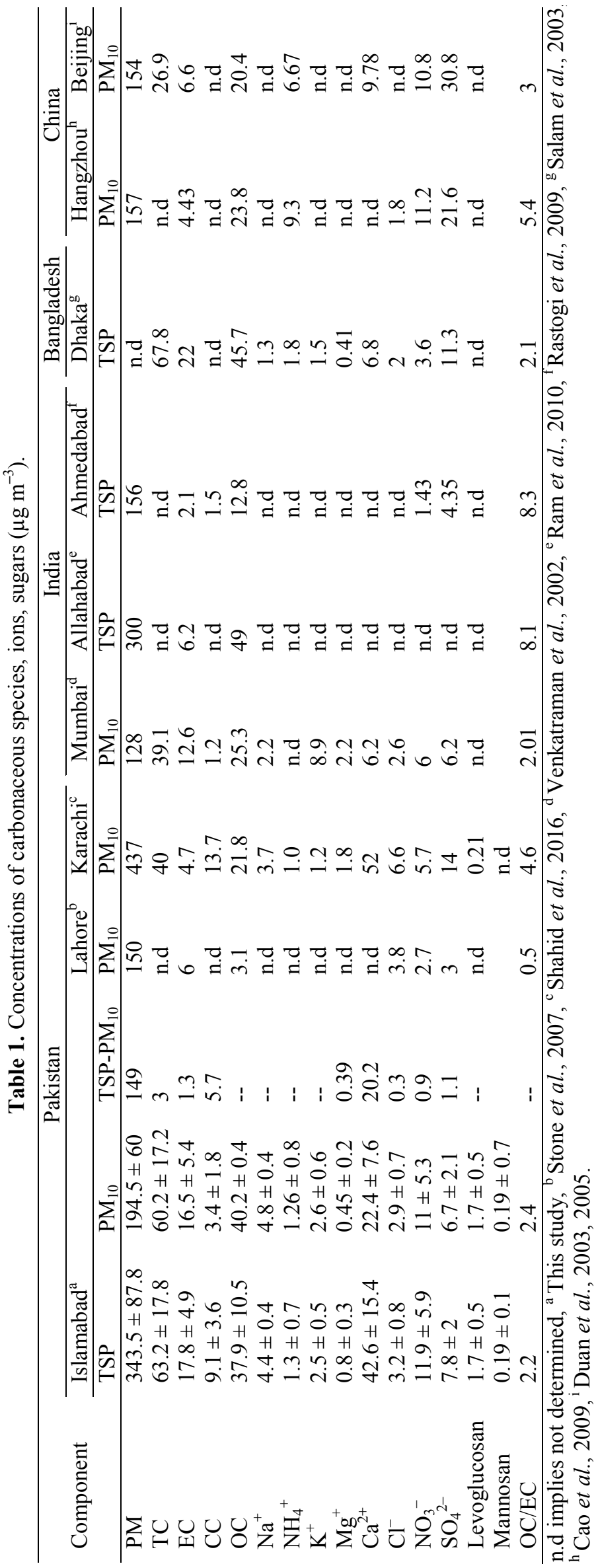




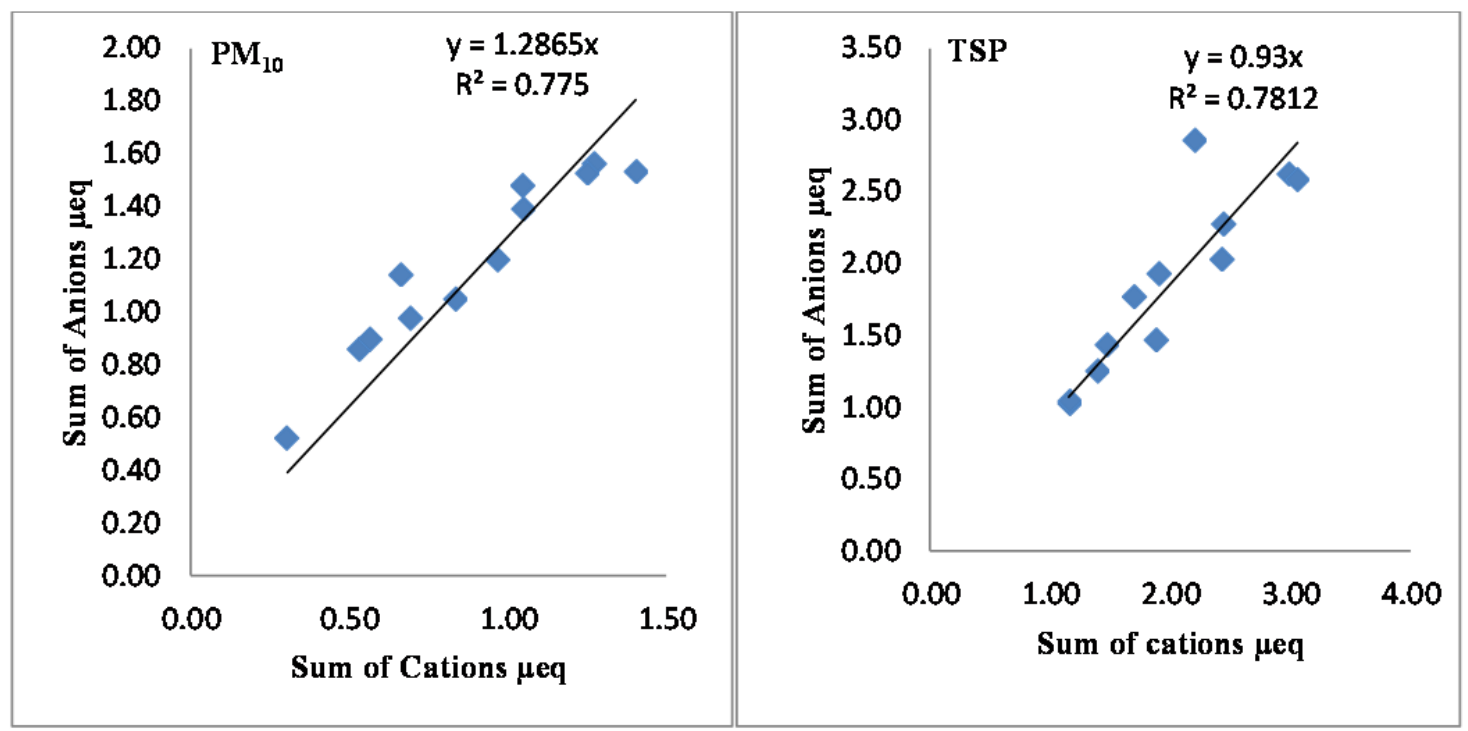

Fig. 4. Correlation between sum of cations and anions.

\section{Size Distribution and Relations between Determined Saccharides}

Total concentrations of analyzed saccharides account to $2.2 \mu \mathrm{g} \mathrm{m}^{-3}$ for TSP and $2.1 \mu \mathrm{g} \mathrm{m}^{-3}$ for $\mathrm{PM}_{10}$, which makes around $1 \%$ of the total particulate matter (TSP and $\mathrm{PM}_{10}$ ). Although saccharides are not a main mass contributor the wide spread of those compounds in the living and burned biomass enhances their relevance in terms of source attribution or particles.

The analysis of the distributions of saccharide concentrations between the TSP and $\mathrm{PM}_{10}$ fractions shows that anhydrosaccharides, i.e., levoglucosan, mannosan and galactosan, all directly related to combustion of biomass are present mainly in $\mathrm{PM}_{10}$, which is in line with expectations for the combustion aerosol sizes (Hosseini et al., 2010). The coarse fraction of saccharides consists of a small share of polyols, as well as primary and secondary saccharides as shown in Fig. 5.

Average levoglucosan concentrations were the same in both fractions $\left(1.70 \mu \mathrm{g} \mathrm{m}^{-3}\right)$ and contribute with $78 \%$ and $83 \%$ to total saccharides in TSP and $\mathrm{PM}_{10}$ respectively. The concentrations of levoglucosan in atmosphere varied from $0.79 \mu \mathrm{g} \mathrm{m}^{-3}$ to $2.58 \mu \mathrm{g} \mathrm{m}^{-3}$ during the whole study period, whereas the relation to $\mathrm{PM}_{10}$ was in stable range of $0.8-1 \%$ in all samples. Levoglucosan showed a strong correlation with mannosan and galactosan, both related to $\mathrm{PM}_{10}$ fraction only (Fig. 6). Their concentrations are respectively one or two orders of magnitude lower than those of levoglucosan, but still higher than the concentration of other determined sugars. Average levoglucosan to mannosan ratio in $\mathrm{PM}_{10}$ was 10 , which is lower than reported for burning of typical Pakistani wood species (20) and typical Asian biomass types $(>30)$, but rather in the range of European residential hardwood burning (Shahid et $a l ., 2015$, and references therein). On the other hand, the ratio of levoglucosan to galactosan of 24 is perfectly in line with what was reported for Asian biomass and most probably this anhydrosaccharidic patterns must be explained by co-firing of wood and other biomass types (e.g., leaves, grasses).

Further components, which were related merely to $\mathrm{PM}_{10}$ were xylitol and glucose. The average concentrations of those compounds in $\mathrm{PM}_{10}$ were much lower than those of anhydrosugars: $0.01 \mathrm{\mu g} \mathrm{m}^{-3}$ for xylitol and $0.03 \mu \mathrm{g} \mathrm{m}^{-3}$ for glucose. Both compounds showed a strong correlation with levoglucosan with slopes (ratio of each compound to levoglucosan) 0.004 and 0.014 for xylitol and glucose respectively. This suggests that both sugars originate from biomass combustion but are respectively 60 and 200 times lower concentrated. Both xylitol and glucose are mainly associated with living biomass, e.g., fungal spores and soil biota, but were reported alike as minor constituents of biomass smoke (Caseiro et al., 2007). The previously proposed co-firing of different biomass types, also wet, non-seasoned wood or green wastes can explain the correlation of xylitol and glucose with levoglucosan in the aerosols from Islamabad. Furthermore, anthropogenic open fires or simple fireplaces placed in the backyards of houses in which firing is linked to the resuspension of soil dust, as it was reported for wildfires (Pio et al., 2008; Ma et al., 2009) are not atypical as well.

Arabitol, mannitol and trehalose were spread among both fractions, whereas on average $77-79 \%$ of arabitol and mannitol contributed to $\mathrm{PM}_{10}$ with variations among single samples reaching 25\%. $\mathrm{PM}_{10}$ fractions of both polyols correlated well with levoglucosan, which points to impact from burning of moldy biomass, as arabitol and mannitol are common fungal spore tracers (Bauer et al., 2008). Trehalose was in $36 \%$ related to $\mathrm{PM}_{10}$ but the contribution varies considerably on different days. Further secondary saccharide, sucrose, was detected only in TSP fraction.

Trehalose was proposed as tracers for soil dust (Simoneit et al., 2004). Also sucrose can be expected in natural soil dust, as significant amount of those secondary saccharides are present in plant debris, which form soils. In the present study, it was observed that only trehalose correlates with 


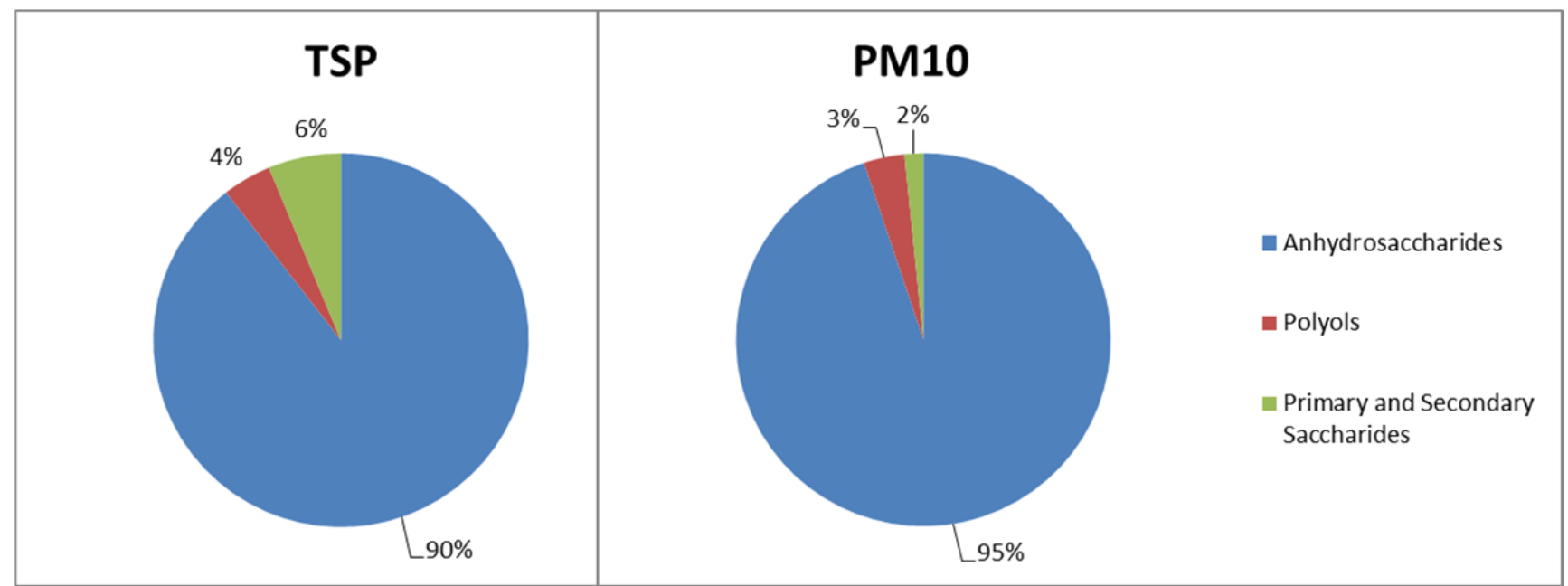

Fig. 5. Share of different saccharide groups in the total saccharide mass in TSP and $\mathrm{PM}_{10}$ fractions.
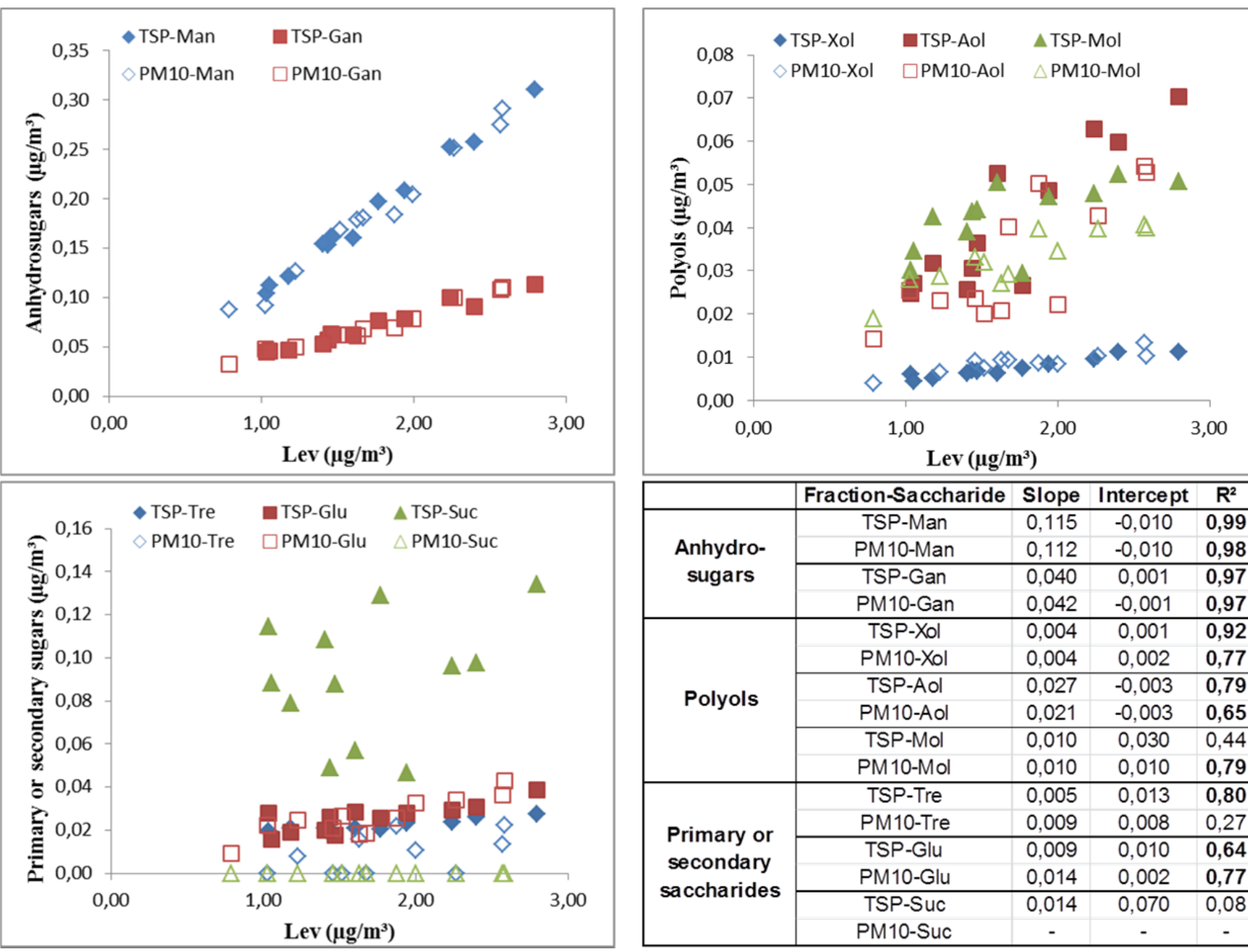

\begin{tabular}{|c|c|c|c|c|}
\hline & Fraction-Saccharide & Slope & Intercept & $\mathbf{R}^{\mathbf{2}}$ \\
\hline \multirow{3}{*}{$\begin{array}{c}\text { Anhydro- } \\
\text { sugars }\end{array}$} & TSP-Man & 0,115 & $-0,010$ & $\mathbf{0 , 9 9}$ \\
\cline { 2 - 5 } & PM10-Man & 0,112 & $-0,010$ & $\mathbf{0 , 9 8}$ \\
\cline { 2 - 5 } & TSP-Gan & 0,040 & 0,001 & $\mathbf{0 , 9 7}$ \\
& PM10-Gan & 0,042 & $-0,001$ & $\mathbf{0 , 9 7}$ \\
\hline \multirow{4}{*}{ Polyols } & TSP-Xol & 0,004 & 0,001 & $\mathbf{0 , 9 2}$ \\
& PM10-Xol & 0,004 & 0,002 & $\mathbf{0 , 7 7}$ \\
\cline { 2 - 5 } & TSP-Aol & 0,027 & $-0,003$ & $\mathbf{0 , 7 9}$ \\
& PM10-Aol & 0,021 & $-0,003$ & $\mathbf{0 , 6 5}$ \\
\cline { 2 - 5 } & TSP-Mol & 0,010 & 0,030 & 0,44 \\
& PM10-Mol & 0,010 & 0,010 & $\mathbf{0 , 7 9}$ \\
\hline \multirow{4}{*}{$\begin{array}{c}\text { Primary or } \\
\text { secondary }\end{array}$} & TSP-Tre & 0,005 & 0,013 & $\mathbf{0 , 8 0}$ \\
\cline { 2 - 5 } saccharides & PM10-Tre & 0,009 & 0,008 & 0,27 \\
\cline { 2 - 5 } & TSP-Glu & 0,009 & 0,010 & $\mathbf{0 , 6 4}$ \\
\cline { 2 - 5 } & PM10-Glu & 0,014 & 0,002 & $\mathbf{0 , 7 7}$ \\
\cline { 2 - 5 } & TSP-Suc & 0,014 & 0,070 & 0,08 \\
& PM10-Suc & - & - & - \\
\hline
\end{tabular}

Fig. 6. Correlation between levoglucosan (Lev) and other saccharides detected in the ambient aerosols in Islamabad.

levoglucosan, as expected for prescribed- or open fires. This correlation is driven by concentrations in coarse particles and disappears in $\mathrm{PM}_{10}$ (Fig. 6). Sucrose shows absolutely no correlation with levoglucosan, which points to another source than combustion of biomass and related soil dust resuspension. Most probably it depicts a presence of larger biological particles, i.e., fragments of plants or insects in the atmosphere. Along with TSP-related fraction of arabitol and mannitol, sucrose is not expected to have a long-standing impact on atmospheric aerosols. The occurrence of those 
sugars in TSP has most probably a local and periodic character and thus shows no distinct relations with other measured TSP constituents. However, also large biological particles in the atmosphere should not be neglected in the discussions, because they can be relevant allergenic factor with high short-time impact.

Galactosan and fructose were either not detected in the samples or were under the detection limits, which points to the fact that non-intensive vegetation influence can be expected in Islamabad during winter period.

Until now saccharide concentrations were not discussed in relation to the region of Islamabad. The measurements done within the study in Karachi during pre-monsoon period (Shahid et al., 2016) showed much lower levoglucosan concentrations $\left(0.21 \mu \mathrm{g} \mathrm{m}^{-3}\right)$ by higher total $\mathrm{PM}_{10}$ levels. Regarding the discrepancies in climate conditions it can be expected that this contribution is related to cooking stoves used in the residential kitchens and the enrichment seen during winter in Islamabad can be attributed mainly to heating purposes. Recent measurements reported for Nepal (Wan et $a l ., 2017)$ showed very similar distributions of anhydrosugars during the seasons with levoglucosan concentration of $1.16 \mu \mathrm{g} \mathrm{m}^{-3}$ during wintertime and $0.77 \mu \mathrm{g} \mathrm{m}^{-3}$ during premonsoon season. Also the ratios between anhydrosaccharides were in the similar range as those reported here and in previous work conducted in Karachi, which shows that a certain stability of biomass burning constituents can be assumed in the large region of Indo-Gangetic Plain in the line from north until the coastal zones.

\section{Contribution of Biomass Smoke to Ambient Aerosol}

Levoglucosan and mannosan were shown to be the main saccharides in the aerosols from Islamabad, which points to significant contribution of biomass burning to particulate matter, specifically to its $\mathrm{PM}_{10}$ fraction. The levoglucosan has been used as a tracer for biomass burning (Wang et al., 2007; Lanz et al., 2008; Schmidl et al., 2008; Caseiro et al., 2009; Shahid et al., 2015; Shahid et al., 2016; Wan et al., 2017). Also further components can be seen as indications of biomass burning. Among here analyzed components the water-soluble potassium $\left(\mathrm{K}^{+}\right)$poses an alternative (e.g., Duan et al., 2004). $\mathrm{K}^{+}$was similarly to levoglucosan found mainly in the $\mathrm{PM}_{10}$ fraction and showed a good correlation with levoglucosan if TSP concentrations are considered (Table S1). Nevertheless, $\mathrm{K}^{+}$is less unique than levoglucosan as wood burning marker and since it was reported also as constituent of soil dust and sea spray (Pachon et al., 2013) it might be burdened with high uncertainty as tracer for biomass burning. In order to calculate contribution of biomass smoke to ambient aerosol a simplified method has been used, i.e., by using a source specific tracer and OC concentrations (Zhang et al., 2008a; Zhang et al., 2010). The emission factors of levoglucosan, expressed as a fraction of OC on carbon/carbon basis $\mu \mathrm{gC}(\mu \mathrm{gC})^{-1}$, from previous biomass studies in Asia and USA are given in Table S2. For commonly used South Asian biofuels, such as rice straw, dried cow dung patties, leaves and briquettes, an average emission factor of $12.6\left[0.079 \mu \mathrm{g}\right.$ levoglucosan $\left.(\mu \mathrm{g} \mathrm{OC})^{-1}\right]$ has been reported (Sheesley et al., 2003). Sullivan et al.
(2008) reported approximately the same emission factor in a chamber studies in Taiwan and USA. While in China an average emission factor of $3.7 \%$ has been reported in a chamber experiment for burning of rice straw (Zhang et al., 2007). In a recent study Zhang et al. (2010) have used an average emission factor 3.6\% [0.080 $\mu \mathrm{g}$ levoglucosan $\left.(\mu \mathrm{g} \mathrm{OC})^{-1}\right]$ to calculate the contribution of biomass to $\mathrm{OC}$ in China. Higher emission factor has been reported in fireplace experiments for hard wood and soft wood by Fine et al. $(2001,2002)$ in USA. All these values are given in Table 2. In this study contribution of biomass burning (BB) to OC and PM have been calculated using the factors elaborated previously for Karachi (Shahid et al., 2016), as these are based upon a robust average build for burning of mixed biomass fuels.

$\mathrm{BB}-\mathrm{EC}=$ Levoglucosan $\times 2.7$

BB-PM $=$ Levoglucosan $\times 20$

These relationships have been derived from South Asian biomass source studies comprised in the Table S2. Emission ratios in relation to levoglucosan were calculated for a $53 / 47 \%$ mix of wood and other biomass using wood smoke data from Shahid et al. (2015) and biomass emission data from Sheesley et al. (2003) (Sy) and Zhang et al. (2007) (Z), resulting factors indicated as "Mix" in Table S2. Mix (Sd/Sy) is calculated for using other biomass data from Sheesley et al. (2003); Mix (Sd/Z) uses Zhang et al. (2007) data.

The shares of levoglucosan in OC has been reported in the literature are comprised in Table S2. Calculation of biomass burning contribution is burdened with certain uncertainty, which is primarily related to data used for calculation. As a wide variety of biofuels is used and biomass combustion in Asia seem to have an inter-regional character, e.g., as reported for Indo-Gangetic Plain (Wan et al., 2017), constructing of average values from possibly high number of source studies and regional reports may keep the uncertainty within a limit of a few percent and seem more adequate than strict selection of locally used fuels.

The calculated relative contributions from biomass burning to $\mathrm{EC}, \mathrm{OC}$ and particulate matter $\mathrm{PM}_{10}$ and TSP) have been given in Table 3. Significant contribution of biomass burning (BB) to OC and PM has been found in both $\mathrm{PM}_{10}$ and TSP in Islamabad. In $\mathrm{PM}_{10}$, BB-OC contribution to average $\mathrm{OC}$ was found in the range from $20-60 \%$ with an average of $44 \%$ while for BB-PM contribution to average $\mathrm{PM}_{10}$ mass was found in the range from $8-27 \%$ with an average of $18 \%$. For TSP the BB contribution to the total mass was smaller (10\% in average), but nearly the same for organic carbon, which underlines the fact that both biomass burning aerosols and organic aerosols are mainly consisting of particles with low aerodynamic diameters.

Biomass burning related elemental carbon made on average $26 \%$ of $\mathrm{PM}_{10}$ related $\mathrm{EC}$, which points that previously mentioned traffic is a stronger EC contributor. The BB-EC might be however underestimated, as also after subtraction of BB-EC from the total EC still a good 


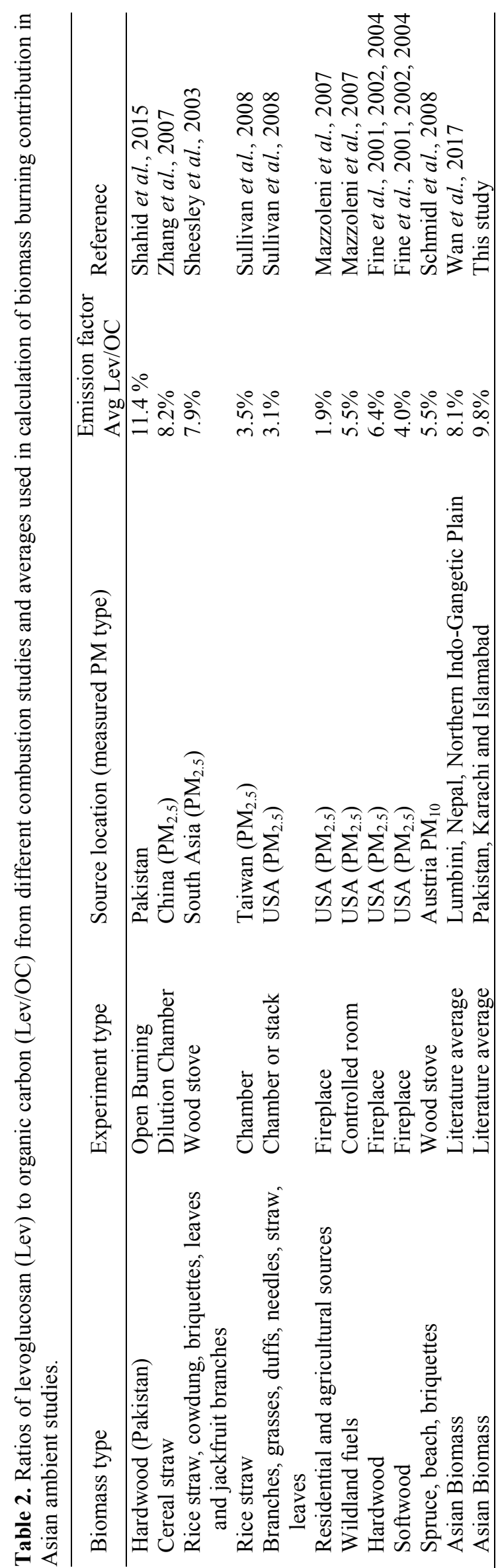

linear relation between EC and levoglucosan is observed. If underestimation is a case it would point to the fact that residential biomass combustion in Islamabad is conducted in higher percentage with wood than with other biomass types (Shahid et al., 2015).

\section{Identified Particle Sources/Types and their Contribution to $P_{10}$ and TSP}

Mass closure of $\mathrm{PM}_{10}$ and TSP has been given in Fig. 7 that indicates that organic matter and calcareous substances contributes a large fraction followed by soluble ions in both $\mathrm{PM}_{10}$ and TSP. OM contributes $18 \%$ in TSP and 34\% in $\mathrm{PM}_{10}$ while carbonates $31 \%$ and $28 \%$ in TSP and $\mathrm{PM}_{10}$ respectively. Shahid et al. (2016) has reported contribution of $\mathrm{OM}$ to $\mathrm{PM}_{10}$ as $34.9 \%$ and carbonates $68 \%$ in Karachi. The unidentified portion in $\mathrm{PM}_{10}$ is less than $2 \%$ as mineral dust and crustal elements are considered to be part of the calcareous substances while for TSP unidentified components are $24 \%$ that might be crustal matter OR mineral dust as trace metals like $\mathrm{Al}$ are missing.

Biomass burning (BB) also contributes to $\mathrm{OC}$ in Islamabad and its contribution to OC mass both in TSP and $\mathrm{PM}_{10}$ has been given in Fig. 8. BB contribution is $45 \%$ of OC-TSP mass and $44 \%$ of OC-PM 10 mass. Anhydrosugars including levoglucosan and mannosan contributes to $5 \%$ and $6 \%$ respectively to OC-PM $\mathrm{PM}_{10}$ and OC-TSP respectively. Thus, major fraction of organic carbon comes from biomass burning.

\section{CONCLUSION}

The $\mathrm{PM}_{10}$, TSP mass, water-soluble ionic species, anhydrosugars, sugar alcohols and carbonaceous fractions were measured in atmospheric aerosol samples collected during wintertime at a residential site in Islamabad. The particulate matter concentrations were found to be very high for both $\mathrm{PM}_{10}$ and TSP, exceeding WHO guidelines (150 $\mu \mathrm{g} \mathrm{m}^{-3}$ for Target I, $100 \mu \mathrm{g} \mathrm{m}^{-3}$ for Target II and $75 \mu \mathrm{g} \mathrm{m}^{-3}$ for Target III). During the study period of 12 days, $\mathrm{PM}_{10}$ concentrations exceeded the WHO Target I limit on 9 days, the Target II limit on 11 days and the Target III limit on all days. The mass closure of $\mathrm{PM}_{10}$ and TSP indicates that $\mathrm{CaCO}_{3}$ contributes $28 \%$ and $31 \%$, respectively. OM contributes the largest share of the $\mathrm{PM}_{10}$ mass (34\%) but only $18 \%$ of the TSP. The mass closure of OC in both these fractions indicates about a $45 \%$ contribution from biomass to $\mathrm{OC}$ in the $\mathrm{PM}_{10}$ and TSP. EC forms $5 \%$ of the TSP and $8 \%$ of the $\mathrm{PM}_{10}$ mass in Islamabad. Biomass smoke, which may originate in residential heating and cooking in the vicinity of the city, forms a major fraction of the organic carbon.

It is evident from the above results that OM, soluble ions and calcareous species are the main components in $\mathrm{PM}_{10}$, while calcareous species, followed by soluble ions and OM, contribute the largest fraction in TSP. However, in order to develop mitigation strategies, comprehensive long-term measurements are required for assessing the source of these pollutants. 
Table 3. PM, OC, Levoglucosan concentrations and contribution of biomass burning (BB) to PM and carbonaceous fraction in Islamabad.

\begin{tabular}{|c|c|c|c|c|c|c|}
\hline & \multicolumn{3}{|c|}{ TSP } & \multicolumn{3}{|c|}{$\mathrm{PM}_{10}$} \\
\hline & Min & Max & Average & Min & Max & Average \\
\hline $\mathrm{PM}\left(\mu \mathrm{g} \mathrm{m}^{-3}\right)$ & 219 & 468 & 343 & 90 & 305 & 194 \\
\hline $\mathrm{OC}\left(\mu \mathrm{g} \mathrm{m}^{-3}\right)$ & 28 & 57 & 38 & 20 & 56 & 40 \\
\hline $\mathrm{EC}\left(\mu \mathrm{g} \mathrm{m}^{-3}\right)$ & 12 & 26 & 18 & 6 & 24 & 16 \\
\hline Levoglucosan $\left(\mu \mathrm{g} \mathrm{m}^{-3}\right)$ & 1.0 & 2.7 & 1.7 & 0.8 & 2.6 & 1.7 \\
\hline $\mathrm{BB}-\mathrm{EC}\left(\mu \mathrm{g} \mathrm{m}^{-3}\right)$ & 2.8 & 7.5 & 4.6 & 2.1 & 7.0 & 4.6 \\
\hline $\mathrm{BB}-\mathrm{OC}\left(\mu \mathrm{g} \mathrm{m}^{-3}\right)$ & 11 & 29 & 17 & 8.0 & 26 & 18 \\
\hline BB-PM $\left(\mu \mathrm{g} \mathrm{m}^{-3}\right)$ & 21 & 56 & 34 & 16 & 52 & 34 \\
\hline Contribution of BB-EC to average EC (\%) & 16 & 42 & 26 & 13 & 42 & 28 \\
\hline Contribution of $\mathrm{BB}-\mathrm{OC}$ to average $\mathrm{OC}(\%)$ & 28 & 75 & 45 & 20 & 66 & 44 \\
\hline Contribution of $\mathrm{BB}$ to average $\mathrm{PM}(\%)$ & 6 & 16 & 10 & 8 & 27 & 18 \\
\hline $\begin{array}{l}\text { Contribution of BB to PM (\%) Karachi, Pakistan, } \\
\text { pre-monsoon (Shahid et al., 2016) }\end{array}$ & - & - & - & 0.41 & 1.8 & 0.96 \\
\hline $\begin{array}{l}\text { Contribution of BB to PM (\%) Lumbini, Nepal, } \\
\text { winter (Wan et al., 2017) }\end{array}$ & 0.01 & 1.3 & 0.47 & - & - & - \\
\hline
\end{tabular}

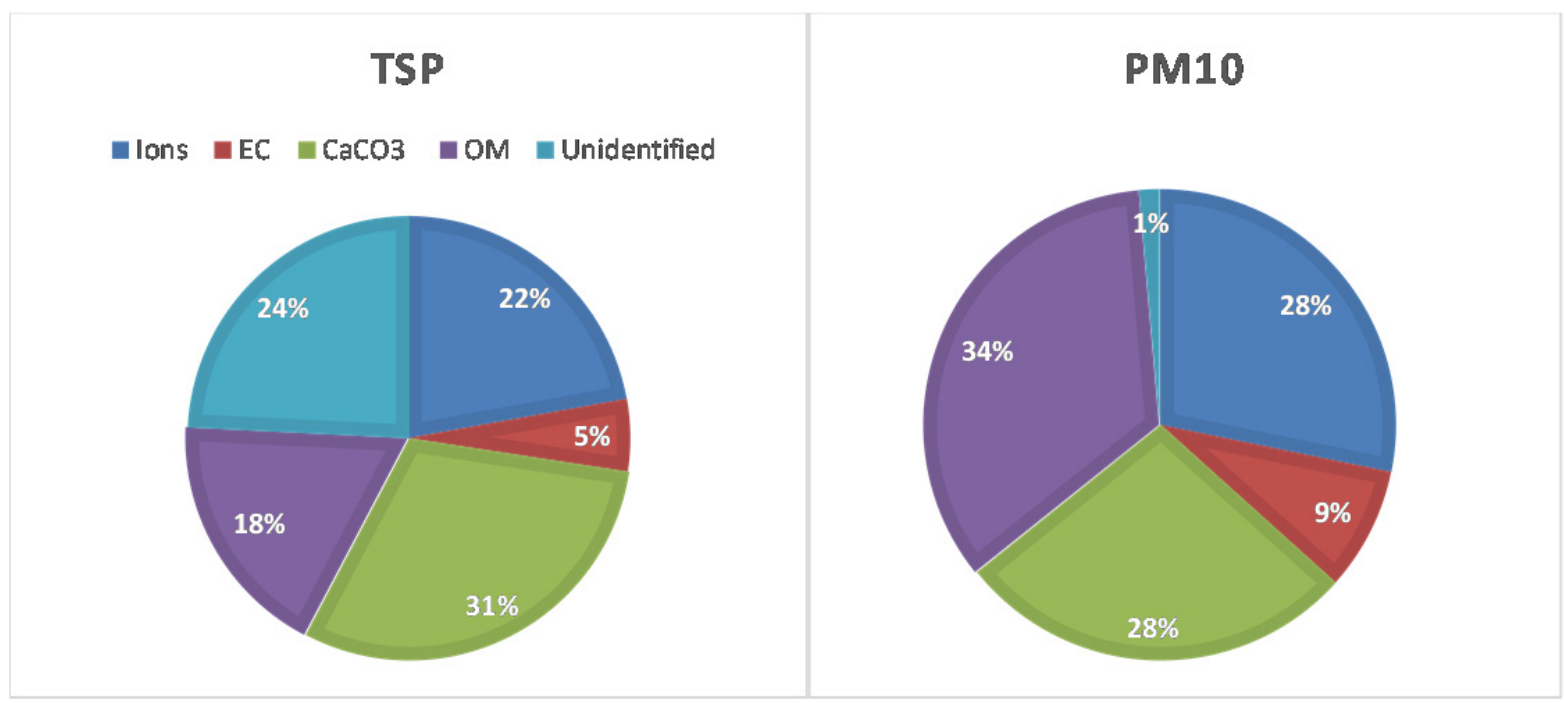

Fig. 7. Mass closure of $\mathrm{PM}_{10}$ and TSP.

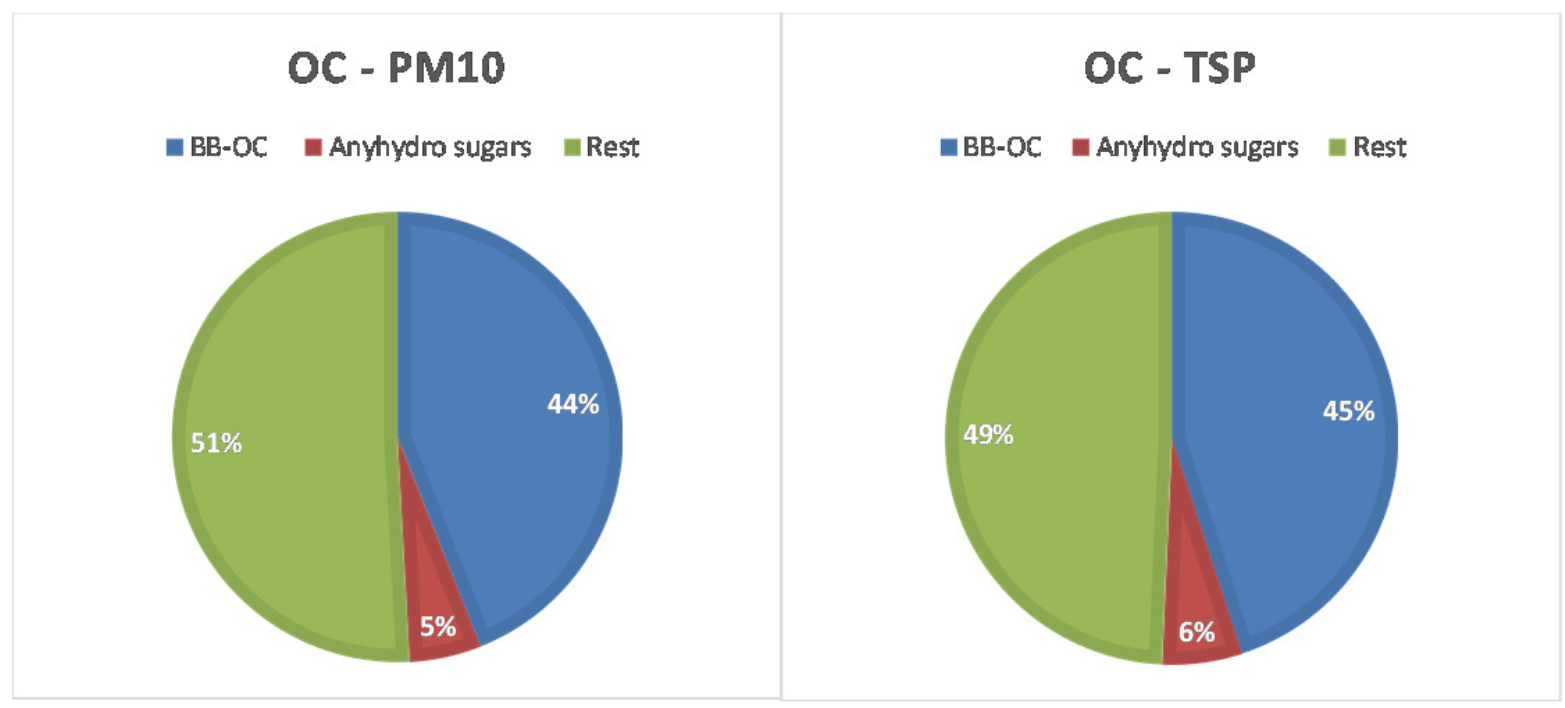

Fig. 8. Mass closure of organic carbon in $\mathrm{PM}_{10}$ and TSP. 


\section{ACKNOWLEDGEMENT}

The authors fully acknowledge the support of Pakistan Environmental Protection Agency (PAKEPA) for their help in sample collection.

\section{SUPPLEMENTARY MATERIAL}

Supplementary data associated with this article can be found in the online version at http://www.aaqr.org.

\section{REFERENCES}

Alam, K., Mukhtar, A., Shahid, I., Blaschke, T., Majid, H., Rahman, S., Khan, R. and Rahman, N. (2014). Source apportionment and characterization of particulate matter $\left(\mathrm{PM}_{10}\right)$ in urban environment of Lahore. Aerosol Air Qual. Res. 14: 1851-1861.

Alvi, M.U. Chishtie, F. Shahid, I. Mahmud, T. and Hussain R. (2018). Traffic- and industry-related air pollution exposure assessment in an Asian megacity. Clean-Soil Air Water 46: 1600773.

Andreae, M.O. and Merlet, P. (2001). Emission of trace gases and aerosols from biomass burning. Global Biogeochem. Cycles 15: 955-966.

Awais M., Shahzad M.I, Nazeer M., Mahmood I., Mehmood S., Iqbal M.F., Yasmin N. and Shahid I. (2018). Assessment of aerosol optical properties using remote sensing over highly urbanized twin cities of Pakistan. J. Atmos. Sol. Terr. Phys. 173: 37-49.

Bauer, H., Claeys, M., Vermeylen, R., Schueller, E., Weinke, G., Berger, A. and Puxbaum, H. (2008). Significant contributions of fungal spores to the organic carbon and to the aerosol mass balance of the urban atmospheric aerosol. Atmos. Environ. 42: 588-593.

Begum, B.A., Hossain, A., Nahar, N., Markwitz, A. and Hopke, P.K. (2012). Organic and black carbon in $\mathrm{PM}_{2.5}$ at an urban site at Dhaka, Bangladesh. Aerosol Air Qual. Res. 12: 1062-1072.

Beig, G., Chate, D.M., Ghude, S.D., Ali, K., Satpute, T., Sahu, S.K., Parkhi, N. and Trimbake, H.K. (2013). Evaluating population exposure to environmental pollutants during Deepavali fireworks displays using air quality measurements of the SAFAR network. Chemosphere 92: 116-124.

Bhaskar B.V. and Mehta V.M. (2010). Atmospheric particulate pollutants and their relationship with meteorology in Ahmedabad. Aerosol Air Qual. Res. 10: 301-315.

Bibi, H., Alam, K., Chishtie, F., Bibi, S., Shahid, I. and Blaschke, T. (2015). Intercomparison of MODIS, MISR, OMI, and CALIPSO aerosol optical depth retrievals for four locations on the Indo-Gangetic plains and validation against AERONET data. Atmos. Environ. 111: 113-126.

Bulbul, G., Shahid, I., Chishtie, F., Shahid, M.Z., Hundal, R.A., Zahra, F. and Shahzad, M.I. (2018). PM $_{10}$ sampling and AOD trends during 2016 winter fog season in the Islamabad region. Aerosol Air Qual. Res. 18: 188-199.

Cachier, H., Bremond, M.P. and Buat Ménard, P. (1989).
Determination of atmospheric soot carbon with a simple thermal method. Tellus B 41: 379-390.

Caseiro, A., Bauer, H., Schmidl, C., Pio, C.A. and Puxbaum, H. (2009). Wood burning impact on $\mathrm{PM}_{10}$ in three Austrian regions. Atmos. Environ. 43: 2186-2195.

Caseiro, A., Marr, I.L., Claeys, M., Kasper-Giebl, A., Puxbaum, H. and Pio, C.A. (2007). Determination of saccharides in atmospheric aerosol using anion-exchange high-performance liquid chromatography and pulsedamperometric detection. J. Chromatogr. A 1171: 37-45.

Chate, D., Beig, G., Satpute, T., Sahu, S.K., Ali, K., Parkhi, N. and Ghude, S. (2013). Assessments of population exposure to environmental pollutants using air quality measurements during Commonwealth Games-2010. Inhalation Toxicol. 25: 333-340.

Chow, J.C., Watson, J.G., Lu, Z., Lowenthal, D.H., Frazier, C.A., Solomon, P.A., Thuillier, R.H. and Magliano, K. (1996). Descriptive analysis of $\mathrm{PM}_{2.5}$ and $\mathrm{PM}_{10}$ at regionally representative locations during SJVAQS/ AUSPEX. Atmos. Environ. 30: 2079-2112.

Duan, F., Liu, X., Yu, T. and Cachier, H. (2004). Identification and estimate of biomass burning contribution to the urban aerosol organic carbon concentrations in Beijing. Atmos. Environ 38: 1275-1282.

Dutkiewicz, V.A., Alvi, S., Ghauri, B.M., Choudhary, M.I. and Husain, L. (2009). Black carbon aerosols in urban air in South Asia. Atmos. Environ. 43: 1737-1744.

Ghauri, B., Lodhi, A. and Mansha, M. (2007). Development of baseline (air quality) data in Pakistan. Environ. Monit. Assess. 127: 237-252.

Ghude, S.D., Beig, G., Kulkarni, P.S., Kanawade, V.P., Fadnavis, S. and Remedios, J.J. (2011). Regional CO pollution over the Indian-subcontinent and various transport pathways as observed by MOPITT. Int. J. Remote Sens. 32: 6133-6148.

Ghude, S.D., Chate, D.M., Jena, C., Beig, G., Kumar, R., Barth, M.C., Pfister, G.G., Fadnavis, S. and Pithani, P. (2016). Premature mortality in India due to $\mathrm{PM}_{2.5}$ and ozone exposure. Geophys. Res. Lett. 43: 4650-4658.

Ghude, S.D., Bhat, G.S., Prabhakaran, T., Jenamani, R.K., Chate, D.M., Safai, P.D., Karipot, A.K., Konwar, M., Pithani, P., Sinha, V., Rao, P.S.P., Dixit, S.A., Tiwari, S., Todekar, K., Varpe, S., Srivastava, A.K., Bisht, D.S., Murugavel, P., Ali, K., Mina, U., Dharua, M., Rao, J., Padmakumari, B., Hazra, A., Nigam, N., Shende, U., Lal, D.M., Chandra, B.P., Mishra, A.K., Kumar, A., Hakkim, H., Pawar, H., Acharja, P., Kulkarni, R., Subharthi, C., Balaji, B., Varghese, M., Bera, S. and Rajeevan, M. (2017). Winter fog experiment over the Indo-Gangetic plains of India. Curr. Sci. 112: 767.

Gray, H.A., Cass, G.R., Huntzicker, J.J., Heyerdahl, E.K. and Rau, J.A. (1986). Characteristics of atmospheric organic and elemental carbon particle concentrations in Los Angeles. Environ. Sci. Technol. 20: 580-589.

Gugamsetty, B., Wei, H., Liu, C., Awasthi, A., Hsu, S., Tsai, C., Roam, G., Wu, Y. and Chen, C. (2012). Source characterization and apportionment of $\mathrm{PM}_{10}, \mathrm{PM}_{2.5}$ and $\mathrm{PM}_{0.1}$ by using positive matrix factorization. Aerosol Air Qual. Res. 12: 476-491. 
Guinot, B., Cachier, H. and Oikonomou, K. (2007). Geochemical perspectives from a new aerosol chemical mass closure. Atmos. Chem. Phys. 7: 1670.

Hildemann, L.M., Markowski, G.R., Jones, M.C. and Cass, G.R. (1991). Submicrometer aerosol mass distributions of emissions from boilers, fireplaces, automobiles, diesel trucks, and meat-cooking operations. Aerosol Sci. Technol. 14: 138-152.

Hosseini, S., Li, Q., Cocker, D., Weise, D., Miller, A., Shrivastava, M., Miller, J.W., Mahalingam, S., Princevac, M. and Jung, H. (2010). Particle size distributions from laboratory-scale biomass fires using fast response instruments. Atmos. Chem. Phys. 10: 8065-8076.

Fine, P.M., Cass, G.R. and Simoneit, B.R.T. (2001). Chemical characterization of fine particle emissions from fireplace combustion of woods grown in the northeastern United States. Environ. Sci. Technol. 35: 2665-2675.

Fine, P.M., Cass, G.R. and Simoneit, B.R.T. (2002). Chemical characterization of fine particle emissions from the fireplace combustion of woods grown in the southern United States. Environ. Sci. Technol. 36: 14421451.

Iinuma, Y., Engling, G., Puxbaum, H. and Herrmann, H. (2009). A highly resolved anion-exchange chromatographic method for determination of saccharidic tracers for biomass combustion and primary bioparticles in atmospheric aerosol. Atmos. Environ. 43: 1367-1371.

Jankowski, N., Schmidl, C., Marr, I.L., Bauer, H. and Puxbaum, H. (2008). Comparison of methods for the quantification of carbonate carbon in atmospheric $\mathrm{PM}_{10}$ aerosol samples. Atmos. Environ. 42: 8055-8064.

Kamal, A., Malik, R.N., Martellini, T. and Cincinelli, A. (2015). Exposure to dust-bound PAHs and associated carcinogenic risk in primitive and traditional cooking practices in Pakistan. Environ. Sci. Pollut. Res. Int. 22: 12644-12654.

Kaushar, A., Chate, D., Beig, G., Srinivas, R., Parkhi, N., Satpute, T., Sahu, S., Ghude, S., Kulkarni, S., Surendran, D., Trimbake, H. and Trivedi, D.K. (2013). Spatiotemporal variation and deposition of fine and coarse particles during the Commonwealth Games in Delhi. Aerosol Air Qual. Res. 13: 748-755

Khillare, P.S., Balachandran, S. and Meena, B.R. (2004). Spatial and temporal variation of heavy metals in atmospheric aerosol of Delhi. Environ. Monit. Assess. 90: 1-21.

Khwaja, H.A., Parekh, P.P., Khan, A.R., Hershey, D.L., Naqvi, R.R., Malik, A. and Khan, K. (2009). An indepth characterization of urban aerosols using electron microscopy and energy dispersive X-ray analysis. Clean-Soil Air Water 37: 544-554.

Lanz, V.A., Alfarra, M.R., Baltensperger, U., Buchmann, B., Hueglin, C., Szidat, S., Wehrli, M.N., Wacker, L., Weimer, S. and Caseiro, A. (2008). Source attribution of submicron organic aerosols during wintertime inversions by advanced factor analysis of aerosol mass spectra. Environ. Sci. Technol. 42: 214-220.
Ma, S., Wang, Z., Bi, X., Sheng, G. and Fu, J. (2009). Composition and source of saccharides in aerosols in Guangzhou, China. Chin. Sci. Bull. 54: 4500-4506.

Pachon, J.E., Weber, R J., Zhang, X., Mulholland, J.A. and Russell, A.G. (2013). Revising the use of potassium (K) in the source apportionment of $\mathrm{PM}_{2.5}$. Atmos. Pollut. Res. 4: 14-21.

Parekh, P.P., Khwaja, H.A., Khan, A.R., Naqvi, R.R., Malik, A., Shah, S.A., Khan, K. and Hussain, G. (2001). Ambient air quality of two metropolitan cities of Pakistan and its health implications. Atmos. Environ. 35: 59715978.

Parkhi, N., Chate, D., Ghude, S.D., Peshin, S., Mahajan, A., Srinivas, R., Surendran, D., Ali, K., Singh, S., Trimbake, H. and Beig, G. (2016). Large inter annual variation in air quality during the annual festival 'Diwali' in an Indian megacity. J. Environ. Sci. 43: 265-272.

Pio, C.A., Legrand, M., Alves, C.A., Oliveira, T., Afonso, J., Caseiro, A., Puxbaum, H., Sanchez Ochoa, A. and Gelencser, A. (2008). Chemical composition of atmospheric aerosols during the 2003 summer intense forest fire period. Atmos. Environ. 42: 7530-7543.

Putaud, J.P., Van Dingenen, R., Dell'Acqua, A., Raes, F., Matta, E., Decesari, S., Facchini, M. and Fuzzi, S. (2004). Size-segregated aerosol mass closure and chemical composition in Monte Cimone (I) during MINATROC. Atmos. Chem. Phys. 4: 889-902.

Puxbaum, H. (1979). Thermo-Gasanalysator zur Charakterisierung von Kohlenstoff- und Schwefelverbindungen in luftgetragenen Stäuben. Fresenius' J. Anal. Chem 298: 250-259.

Qadir, M.A., Zaidi, J.H., Ahmad, S.A., Gulzar, A., Yaseen, M., Atta, S. and Tufail, A. (2012). Evaluation of trace elemental composition of aerosols in the atmosphere of Rawalpindi and Islamabad using radio analytical methods. Appl. Radiat. Isot. 70: 906-910.

Rajput, M., Ahmad, S., Ahmad, M. and Ahmad, W. (2005). Determination of elemental composition of atmospheric aerosol in the urban area of Islamabad, Pakistan. $J$. Radioanal. Nucl. Chem. 266: 343-348.

Ram, K. and Sarin, M. (2010). Spatio-temporal variability in atmospheric abundances of EC, OC and WSOC over Northern India. J. Aerosol Sci. 41: 88-98.

Rastogi, N. and Sarin, M. (2009). Quantitative chemical composition and characteristics of aerosols over western India: One-year record of temporal variability. Atmos. Environ. 43: 3481-3488.

Salam, A., Bauer, H., Kassin, K., Mohammad, S. and Puxbaum, H. (2003). Aerosol chemical characteristics of a mega-city in Southeast Asia (Dhaka-Bangladesh). Atmos. Environ. 37: 2517-2528.

Salma, I., Chi, X. and Maenhaut, W. (2004). Elemental and organic carbon in urban canyon and background environments in Budapest, Hungary. Atmos. Environ. 38: $27-36$.

Sandradewi, J., Prévôt, A., Alfarra, M., Szidat, S., Wehrli, M., Ruff, M., Weimer, S., Lanz, V., Weingartner, E. and Perron, N. (2008). Comparison of several wood smoke markers and source apportionment methods for wood 
burning particulate mass. Atmos. Chem. Phys. Discuss. 8: 8091-8118.

Schauer, J.J., Kleeman, M.J., Cass, G.R. and Simoneit, B.R.T. (1999). Measurement of emissions from air pollution sources. 1. $\mathrm{C}_{1}$ through $\mathrm{C}_{29}$ organic compounds from meat charbroiling. Environ. Sci. Technol. 33: 15661577.

Schauer, J.J., Kleeman, M.J., Cass, G.R. and Simoneit, B.R.T. (2001). Measurement of emissions from air pollution sources. 3. $\mathrm{C}_{1}-\mathrm{C}_{29}$ organic compounds from fireplace combustion of wood. Environ. Sci. Technol. 35: 1716-1728.

Schmidl, C., Bauer, H., Dattler, A., Hitzenberger, R., Weissenboeck, G., Marr, I.L. and Puxbaum, H. (2008). Chemical characterisation of particle emissions from burning leaves. Atmos. Environ. 42: 9070-9079.

Shah, M.H., Shaheen, N. and Jaffar R.M. (2004a). Characterization of selected metals in airborne suspended particulate matter in relation to meteorological conditions. J. Chem. Soc. Pak. 29: 598-604.

Shah, M.H., Shaheen, N. and Jaffar, M. (2004b). Screening of urban aerosol particulate composites for selected metal distribution and their dependence on meteorological parameters. Anal. Chim. 94: 805-815.

Shah, M.H., Shaheen, N., Jaffar, M. and Saqib, M. (2004c). Distribution of lead in relation to size of airborne particulate matter in Islamabad, Pakistan. J. Environ. Manage. 70: 95-100.

Shah, M.H., Shaheen, N., Jaffar, M., Khalique, A., Tariq, S.R. and Manzoor, S. (2006). Spatial variations in selected metal contents and particle size distribution in an urban and rural atmosphere of Islamabad, Pakistan. $J$. Environ. Manage. 78: 128-137.

Shah, M.H. and Shaheen, N. (2007). Statistical analysis of atmospheric trace metals and particulate fractions in Islamabad, Pakistan. J. Hazard. Mater. 147: 759-767.

Shah, M.H. and Shaheen, N. (2008). Annual and seasonal variations of trace metals in atmospheric suspended particulate matter in Islamabad, Pakistan. Water Air Soil Pollut. 190: 13-25.

Shah, M.H. and Shaheen, N. (2010). Seasonal behaviors in elemental composition of atmospheric aerosols collected in Islamabad, Pakistan. Atmos. Res. 95: 210-223.

Shah, I.H. and Zeeshan, M. (2016). Estimation of light duty vehicle emissions in Islamabad and climate cobenefits of improved emission standards implementation. Atmos. Environ. 127: 236-243.

Shahid, I., Kistler, M., Mukhtar, A., Ramirez-Santa Cruz, C., Bauer, H. and Puxbaum, H. (2015). Chemical composition of particles from traditional burning of Pakistani wood species. Atmos. Environ. 121: 35-41.

Shahid, I., Kistler, M., Mukhtar, A., Badar M Ghauri, Ramirez-Santa Cruz, C., Bauer, H. and Puxbaum, H. (2016). Chemical characterization and mass closure of $\mathrm{PM}_{10}$ and $\mathrm{PM}_{2.5}$ at an urban site in Karachi Pakistan. Atmos. Environ. 128: 114-123.

Shahid, I., Alvi, M.U., Shahid, M.Z., Alam, K. and Chishtie, F. (2018). Source apportionment of $\mathrm{PM}_{10}$ at an urban site of a south Asian mega city. Aerosol Air Qual.
Res. 18: 2498-2509.

Shahid, M.Z., Hong, L., Yu-Lu, Q. and Shahid, I. (2015a). Source sector contributions to aerosol levels in Pakistan Atmos. Oceanic Sci. Lett. 8: 308-313.

Shahid, M.Z. Liao, H., Li, J., Shahid, I., Lodhi, A. and Mansha, M. (2015b). Seasonal Variations of aerosols in Pakistan: Contributions of domestic anthropogenic emissions and transboundary transport. Aerosol Air Qual. Res. 15: 1580-1600.

Shandilya, K.K., Khare, M. and Gupta, A.B. (2007). Suspended particulate matter distribution in ruralindustrial Satna and in urban-industrial South Delhi. Environ Mont. Assess. 128: 431-445.

Sheesley, R.J., Schauer, J.J., Chowdhury, Z., Cass, G.R. and Simoneit, B.R.T. (2003). Characterization of organic aerosols emitted from the combustion of biomass indigenous to South Asia. J. Geophys. Res. 108: 4285.

Siddique, N., Waheed, S., Daud, M., Markwitz, A. and Hopke, P.K. (2012). Air quality study of Islamabad: Preliminary results. J. Radioanal. Nucl. Chem. 293: 351-358.

Simoneit, B.R.T., Elias, V.O., Kobayashi, M., Kawamura, K., Rushdi, A.I., Medeiros, P.M., Rogge, W.F. and Didyk, B.M. (2004). Sugars - dominant water-soluble organic compounds in soils and characterization as tracers in atmospheric particulate matter. Environ. Sci. Technol. 38: 5939-5949.

Singh, N., Mhawish, A., Deboudt, K., Singh, R.S. and Banerjee, T. (2017). Organic aerosols over Indo-Gangetic Plain: Sources, distributions and climatic implications. Atmos. Environ. 157: 59-74.

Stone, E., Schauer, J., Quraishi, T.A. and Mahmood, A. (2010). Chemical characterization and source apportionment of fine and coarse particulate matter in Lahore, Pakistan. Atmos. Environ. 44: 1062-1070.

Sudheer, A. and Sarin, M. (2008). Carbonaceous aerosols in MABL of Bay of Bengal: Influence of continental outflow. Atmos. Environ. 42: 4089-4100.

Sudheer, A.K. and Rengarajan, R. (2012). Atmospheric mineral dust and trace metals over urban environment in western India during winter. Aerosol Air Qual. Res. 12: 923-933.

Sullivan, A., Holden, A., Patterson, L., McMeeking, G., Kreidenweis, S., Malm, W., Hao, W., Wold, C. and Collett, J. Jr. (2008). A method for smoke marker measurements and its potential application for determining the contribution of biomass burning from wildfires and prescribed fires to ambient $\mathrm{PM}_{2.5}$ organic carbon. $J$. Geophys. Res. 113: D22302.

Turpin, B., Cary, R. and Huntzicker, J. (1990). An in situ, time-resolved analyzer for aerosol organic and elemental carbon. Aerosol Sci. Technol. 12: 161-171.

Turpin, B.J. and Huntzicker, J.J. (1995). Identification of secondary organic aerosol episodes and quantitation of primary and secondary organic aerosol concentrations during SCAQS. Atmos. Environ. 29: 3527-3544.

Turpin, B.J. and Lim, H.J. (2001). Species contributions to $\mathrm{PM}_{2.5}$ mass concentrations: Revisiting common assumptions for estimating organic mass. Aerosol Sci. 
Technol. 35: 602-610.

Venkataraman, C., Reddy, C.K., Josson, S. and Reddy, M.S. (2002). Aerosol size and chemical characteristics at Mumbai, India, during the INDOEX-IFP 1999. Atmos. Environ. 36: 1979-1991.

Wan, X., Kang, S., Li, Q., Rupakheti, D., Zhang, Q., Guo, J., Chen, P., Tripathee, L., Rupakheti, M., Panday, A.K., Wang, W., Kawamura, K., Gao, S., Wu, G. and Cong, Z. (2017). Organic molecular tracers in the atmospheric aerosols from Lumbini, Nepal, in the northern IndoGangetic Plain: Influence of biomass burning. Atmos. Chem. Phys. 17: 8867-8885.

Wedepohl, K.H. (1995). The composition of the continental crust. Geochim. Cosmochim. Acta 59: 1217-1232.

Zhang, T., Claeys, M., Cachier, H., Dong, S., Wang, W., Maenhaut, W. and Liu, X. (2008a). Identification and estimation of the biomass burning contribution to Beijing aerosol using levoglucosan as a molecular marker. Atmos. Environ. 42: 7013-7021.
Zhang, Y., Shao, M., Zeng, L., He, L., Zhu, B., Wei, Y. and Zhu, X. (2007). Source profiles of particulate organic matters emitted from cereal straw burnings. $J$. Environ. Sci. 19: 167-175.

Zhang, Y., Quraishi, T. and Schauer, J.J. (2008b). Daily variations in sources of carbonaceous aerosol in Lahore, Pakistan during a high pollution spring episode. Aerosol Air Qual. Res. 8: 130-146.

Zhang, Z., Engling, G., Lin, C.Y., Chou, C.C.K., Lung, S.C.C., Chang, S.Y., Fan, S., Chan, C.Y. and Zhang, Y.H. (2010). Chemical speciation, transport and contribution of biomass burning smoke to ambient aerosol in Guangzhou, a mega city of China. Atmos. Environ. 44: 3187-3195.

Received for review, December 31, 2017

Revised, June 4, 2018

Accepted, July 4, 2018 